\title{
PROMOVENDO O ENSINO-APRENDIZAGEM DE EDUCAÇÃO AMBIENTAL NO ENSINO FUNDAMENTAL COM JOGOS BASEADOS EM FERRAMENTAS COMPUTACIONAIS
}

\author{
Rodney Cezar de Albuquerque, PGIE/UFRGS, CEFET de Química de Nilópolis/RJ - \\ Unidade Paracambi, rodney.albuquerque@gmail.com \\ Antônio Carlos de Miranda, UNIPLI, mirantam@ig.com.br \\ Ricardo Esteves Kneipp, FAMINAS, IST Petrópolis, kneipp.ist@lncc.br
}

\begin{abstract}
RESUMO: Historicamente o jogo está presente como prática habitual de diversos povos. Concebe-se nele uma atividade lúdica, que, por sua vez, é reconhecidamente motivadora no processo de ensino-aprendizagem. Diante do surgimento de novas tecnologias como o computador e a Internet, escolas e professores passaram a ter acesso ao uso de recursos que excedem a visão tradicional e aos métodos discursivos no processo de ensino-aprendizagem.

Dessa forma, o jogo na web pode transformar-se em uma alternativa importante, nesse processo. Desse modo, este trabalho visa o desenvolvimento, através de ferramentas computacionais (Gane, 1999), de quatro jogos. Para o desenvolvimento dos jogos, escolheu-se um tema recente: o uso racional da água. Posteriormente, foi feito um estudo prévio do ambiente de desenvolvimento onde se analisa o mecanismo de navegação na web, as ferramentas propícias para o desenvolvimento e o conteúdo e o conteúdo a ser utilizado em consonância com o descrito pelo MEC. O jogo desenvolvido apresenta uma interface voltada a web, onde foi utilizada a ferramenta Flash, para a criação de jogos que apresentem recursos multimídia, os quais permitem que o usuário aprenda de forma lúdica.
\end{abstract}

Palavras-chave: Aprendizagem, Ensino, Jogo, Lúdico, Web.

\section{PROMOVING TEACHING-LEARNING OF ENVIRONMENTAL EDUCATION IN BASIC EDUCATION WITH GAMES BASED ON COMPUTACIONAIS TOOLS}

\begin{abstract}
Historically this is the game as practice of various peoples. It designs it is a leisure activity, which in turn is motivating known in the teaching-learning. Faced with the emergence of new technologies such as computer and the Internet, schools and teachers have been given access to the use of resources that go beyond the traditional vision and methods discourse in the teaching-learning.

Thus, the game on the web can turn into an important alternative in that process. Thus, this work aims at the development, through computational tools (Gane, 1999), four games. For the development of games, chose to be a recent theme: the rational use of water. It was subsequently made a preliminary study of the development environment, where it examines the mechanism for web browsing, the tools conducive to the development and content and content to be used in line with that described by the MEC. The game provides an interface geared developed the web, where the tool was used Flash to create games that provide multimedia resources, which allow the user to learn how to play.
\end{abstract}

Keywords: Learning, teaching, games, Ludic, Web. 


\section{Introdução}

A 'vida moderna' força a todos buscar, em suas especialidades, soluções para um mundo melhor, sendo que em geral há uma maior preocupação com as recentes crises mundiais do que com a redução das limitadas reservas naturais. Aquelas, obviamente, estão mais presentes na mídia. Portanto, torna-se necessário para preservar o meio ambiente que instrumentos educacionais, alcancem o mais rapidamente possível os jovens em idade escolar.

Assim, objetivo dessa investigação é desenvolver através de ferramentas computacionais um jogo que possibilite ao aluno fixar conhecimentos de educação ambiental, especificamente da utilização racional da água, na disciplina de ciências na segunda série do ensino fundamental; e ainda, habilitar o docente a utilizar o jogo como recurso didático para a fixação do conhecimento. Desse modo, possibilitar aos alunos que se posicionem de maneira crítica, responsável e construtiva na aquisição da compreensão da importância do meio ambiente numa visão global do planeta Terra, dos seus problemas, que atingem a todos os habitantes desse planeta e do seu papel, enquanto cidadãos, no sentido de ter responsabilidade ética e crítica.

Sob a perspectiva sócio-econômica, a escassez de recursos de água potável e os custos cada vez mais elevados para obtê-los, têm um impacto considerável sobre o desenvolvimento da indústria, da agricultura, da vida e do crescimento econômico (Agenda 21, 1996).

O artigo 21, inciso XIX, da CF88 (Constituição Federal Brasileira de 1988), estabelece a competência da União para "instituir o sistema nacional de gerenciamento de recursos hídricos e definir critérios de outorga de direitos de seu uso". Para atingir este desiderato, foi legislada a lei federal no. 9.433/97 que determina o gerenciamento descentralizado dos recursos hídricos, permitindo uma ampliação do espaço público para a participação do poder estatal, dos usuários e das comunidades.

Diante deste contexto apresentado pela legislação brasileira, a disciplina de ciências, assim como as demais, de forma transdisciplinar, são instrumentos de formação para o fomento de debate, efetivando, por conseqüência, a participação pública na gestão dos recursos hídricos.

Este é o caminho para que cada indivíduo mude de hábitos e assuma novas atitudes que levem à diminuição da degradação ambiental, promovam a melhoria da qualidade de vida e reduzam a pressão sobre os recursos ambientais. A educação ambiental deve ser entendida como educação política, no sentido de que ela reivindica e prepara os cidadãos para exigir justiça social, cidadania nacional e planetária, autogestão e ética nas relações sociais e com a natureza (Agenda 21, 1996).

Buscando influir decisivamente na formação de cidadãos conscientes dos seus direitos e deveres, o presente projeto tem como base de pesquisa um grupo de crianças de sete a dez anos, na fase escolar, que servirão de sujeito para a pesquisa. A partir desse grupo, verificar-se-á a importância do lúdico no aprendizado da criança.

Segundo Brenelli (1996), a utilização do lúdico no aprendizado da criança é muito antiga, vem dos gregos e romanos e, de acordo com os novos ideais de ensino, o jogo deve ser utilizado para facilitar as tarefas escolares.

Importante para o desenvolvimento físico, intelectual e social, o jogo vem ampliando sua importância deixando de ser um simples divertimento e tornando-se a ponte entre a infância e a vida adulta. Seu uso é favorecido pelo contexto lúdico, oferecendo à criança a oportunidade de utilizar a criatividade, o domínio de si, à afirmação da personalidade, 
o imprevisível. O que agrada a criança é a dificuldade e o desafio a ser vencido. Através dele, a criança aprende o que é uma tarefa, a organizar-se e a aceitar o código lúdico, com um contrato social implícito (Brenelli, 1996).

O jogo como exercício preparatório desenvolve nas crianças suas percepções, sua inteligência, suas experimentações e seus instintos sociais. Por meio de uma atividade lúdica, a criança assimila ou interpreta a realidade. (Piaget, 1967) .

$\mathrm{O}$ brincar tem sua origem na situação imaginada que foi criada pela criança, que ao realizar seus desejos, reduz as tensões e constituir uma maneira de acomodação de conflitos e frustrações. O mais importante não é a similaridade do objeto com a coisa imaginada, mas o gesto, tornando seu significado mais importante que o próprio objeto. Assim, a grande importância do jogo no desenvolvimento deve-se ao fato de criar novas relações entre situações dos pensamentos e situações reais (Vygotsky, 1984).

Os jogos educativos com fins pedagógicos revelam a sua importância em situações de ensino-aprendizagem ao aumentar a construção do conhecimento, introduzindo propriedades do lúdico, do prazer, da capacidade de iniciação e ação ativa e motivadora, possibilitando o acesso da criança a vários tipos de conhecimentos e habilidades. Para tal, o jogo deve propiciar diversão, prazer e até mesmo desprazer, quando escolhido voluntariamente, ensinando algo que complete o indivíduo em seu saber, seus conhecimentos e sua percepção do mundo.

Os jogos educativos computadorizados são criados com a finalidade dupla de entreter e possibilitar a aquisição de conhecimento (Antunes, 1998).

\section{Material e Métodos}

Os jogos foram desenvolvidos utilizando a ferramenta Macromedia Flash e o actionScript. O Macromedia Flash é um software para desenvolvimento de animações tanto para Web como para Cd-rom utilizando tecnologia vetorial, tecnologia esta utilizada para construir objetos e animações e a linguagem de programação actionScript desenvolvida de acordo com as especificações da ECMA-262. É considerada uma linguagem orientada a objetos completa, pois possibilita encapsulamento, herança e polimorfismo), serviu de base para outras linguagens como o javaScript e o Jscript.

O grande sucesso das animações feitas em Flash se deve ao fato de ele utilizar a tecnologia vetorial para construir os objetos e as animações, proporcionando arquivos pequenos, além de ser possível visualizar o carregamento através do navegador, de forma que podemos exibir uma mensagem informando que o site está sendo carregado, enquanto o filme não carrega totalmente.

O actionScript foi desenvolvido seguindo as especificações da ECMA-262 (padrão que define o JavaScript). Pode ser considerada uma linguagem orientada a objetos completa, pois possibilita encapsulamento, herança e polimorfismo, que também serviu de base para outras linguagens como o javaScript e o Jscript.

Um site ou uma animação no Flash é composta de elementos gráficos e de texto que normalmente são encapsulados em instâncias que podem ser: graphic, movieClip ou button.

\section{"Jogo de Perguntas e Respostas"}

O jogo apresenta dez perguntas do conteúdo "Planeta Água", da disciplina de ciências da segunda série do ensino fundamental, onde para cada pergunta, existem três opções 
de resposta, opções A, B e C. Ao clicar na opção errada, aparecerá uma mensagem indicando o erro e o possibilitando de jogar novamente. Ao acertar, o jogo o encaminha para a próxima pergunta. Ao término do jogo é emitida uma mensagem de parabéns pelo sucesso no jogo.

O jogo busca avaliar os conhecimentos obtidos pelo aluno após a apresentação do conteúdo pelo professor.

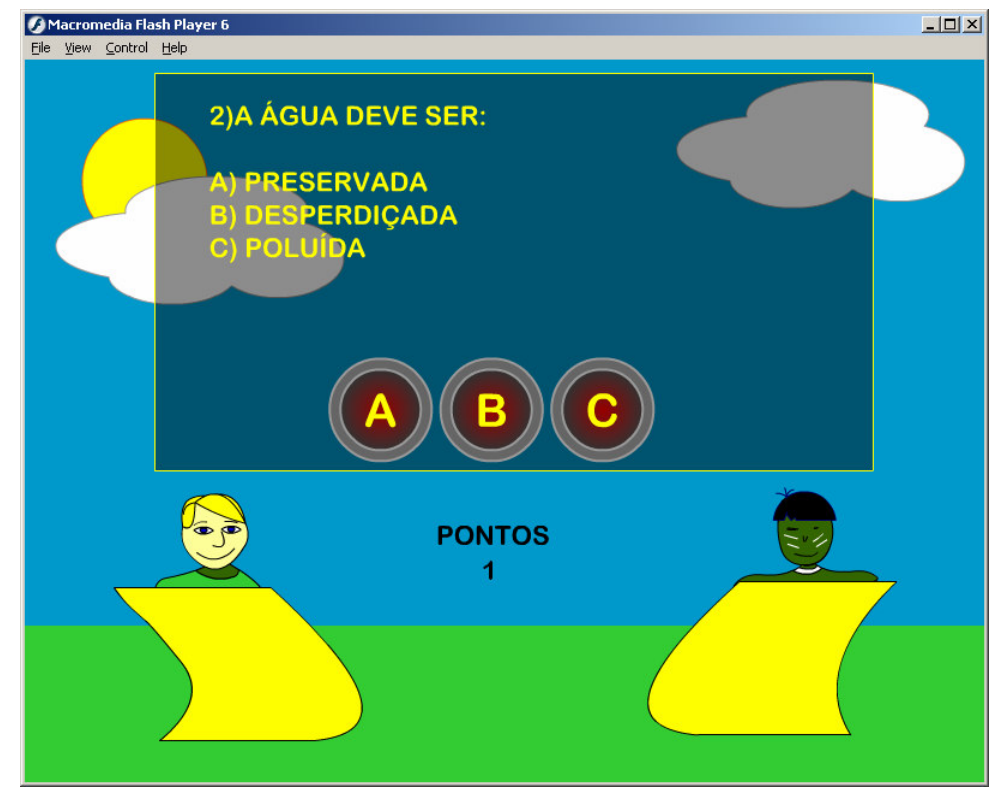

\section{"Jogo Limpe o Rio"}

O jogo "limpe o rio", apresenta um cenário de um rio poluído, propondo ao jogador que ajude nas despoluição do rio, através da retirada de objetos que não façam parte do diaa-dia dos rios, jogando-os na lata do lixo. Ao término do jogo será emitida uma mensagem de parabéns, pela ajuda da despoluição do rio. 


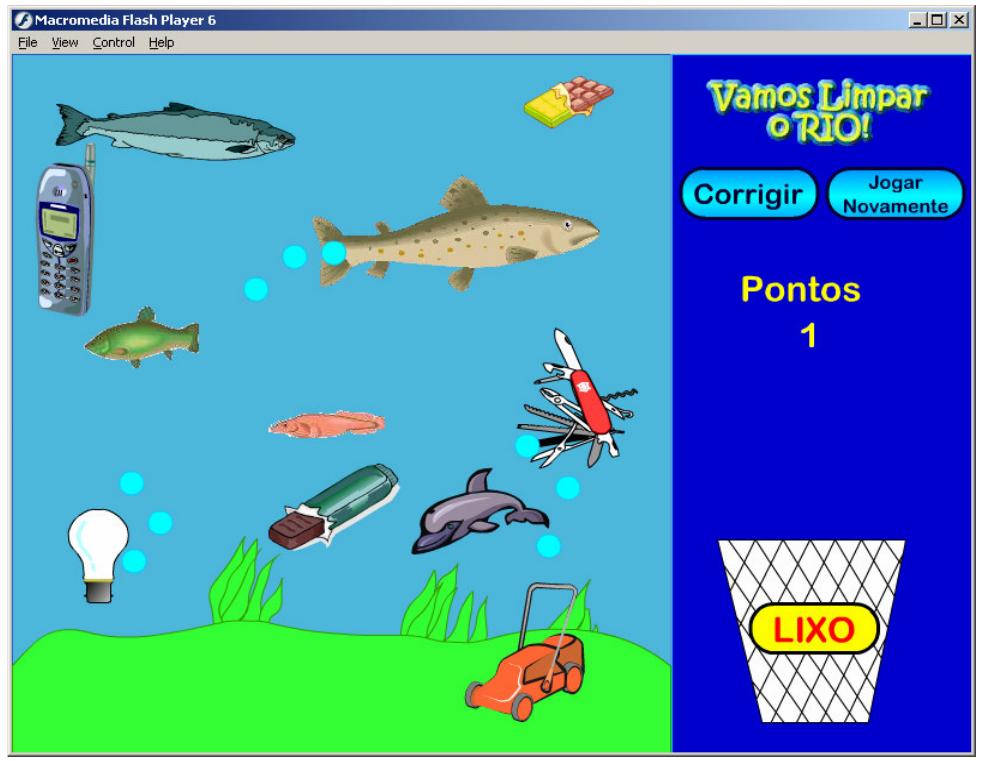

O jogo busca conscientizar ao aluno através do lúdico, que vários objetos ao serem jogados no rio, o poluirão.

\section{"Decifre o Enigma"}

O jogo "Decifre o enigma", apresenta um cenário com uma frase com conteúdo referente ao "Planeta Água", do primeiro ciclo da educação fundamental, pelo qual o aluno deverá substituir os códigos e descobrir a frase através dos enigmas.

Para descobrir a frase, troque o ponto de interrogação (?) pela letra correspondente a figura representativa. O jogo termina quando todas as letras do enigma forem colocadas em seus lugares formando a frase secreta! Ao concluir a frase será emitida uma mensagem de parabéns pela conclusão do jogo. O jogo apresenta um conteúdo multidisciplinar (ciências, português e lógica matemática), trabalhando habilidades como o estimulo verbal ou lingüística e a estimulação lógico matemática.

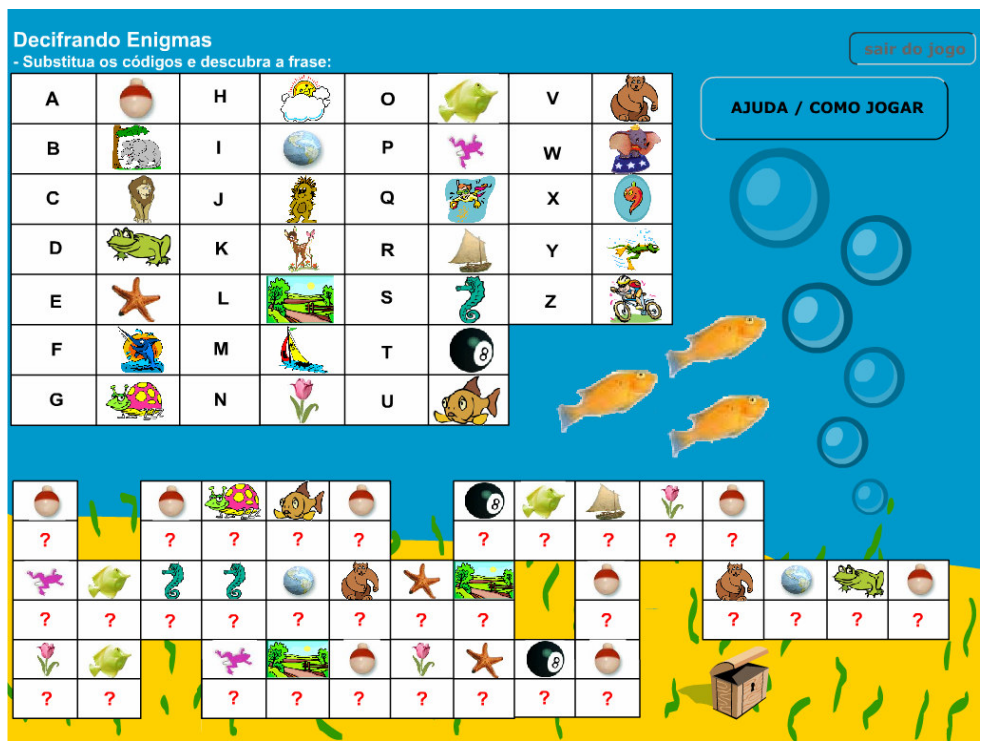




\section{“Quebra-cabeça”}

O jogo "Quebra-cabeça" apresenta um cenário do rio Muriaé, rio pelo qual corta a cidade de Itaperuna, rio esse, conhecido pelos alunos. Esse rio apresenta um pequeno grau de poluição, nas disciplinas de ciências, português, inglês ele é citado, existindo no colégio um trabalho de conscientização junto aos alunos à respeito da importância desse rio para a cidade. Diante dessa preocupação ao desenvolver o jogo quebra-cabeça que tem como objetivo estimular a inteligência espacial da criança (ANTUNES, 2002, p. 110), utilizou-se a foto do rio Muriaé, onde se faz com que o aluno ao jogar lembre de todo trabalho de conscientização feito em sala de aula.

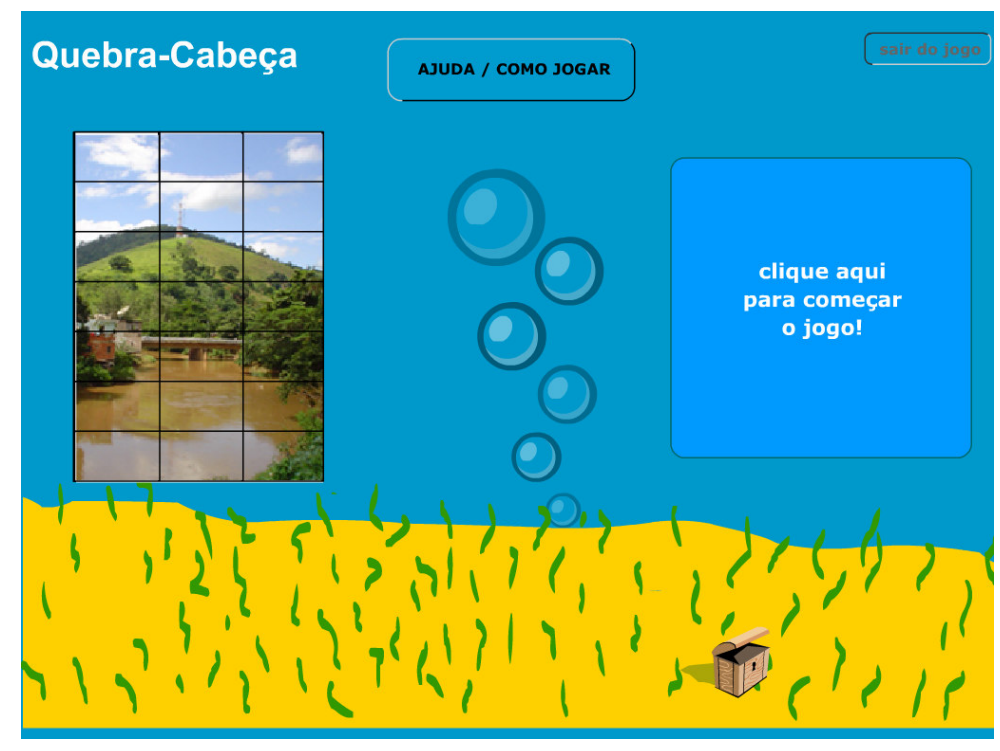

\section{Resultados e Discussão}

Os resultados relatados abaixo, foram obtidos através de:

Entrevistas e de questionários preenchidos, após a utilização do jogo (Chizzotti, 2003).

Resumidamente, os resultados obtidos com os alunos, de maneira geral, foram:

$80 \%$ dos alunos consideram os jogos fáceis

Todos os alunos (100\%) foram favoráveis a utilização destes jogos, em sala de aula.

Todos os alunos (100\%) consideram importante o uso de jogos educativo no aprendizado escolar.

$50 \%$ dos alunos apontaram a necessidade de preservação do meio ambiente

$46 \%$ dos alunos mencionaram a importância de não jogar lixo no rio, e mantê-lo limpo.

$4 \%$ descreveram que já havia tido contato, anteriormente na escola, com o conteúdo programático apresentado no jogo.

$70 \%$ dos alunos apontaram o jogo "Decifre o Enigma" como o mais difícil.

$80 \%$ dos alunos disseram que o jogo mais fácil é "Limpe o Rio".

Análise dos professores:

$80 \%$ descreveram que o jogo apresenta-se didaticamente correto para o ensino fundamental. 


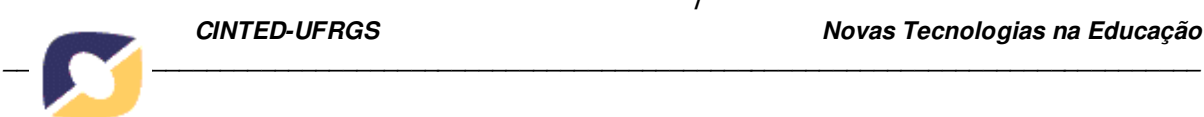

$80 \%$ apontaram que o jogo apresenta uma interface amigável e adequada para a faixa etária de 7 a 10 anos.

Todos (100\%) identificaram mudanças nas atitudes dos alunos, após a utilização do jogo.

Todos (100\%) perceberam maior motivação dos alunos, em sala de aula, em discutir questões relativas à água após a aplicação do jogo

$80 \%$ mencionaram que houve repercussão no colégio, em relação ao uso adequado da água.

\section{Conclusões}

Após o desenvolvimento, os jogos, foram submetidos à avaliação de alunos e professores, como sujeitos de pesquisa do trabalho apresentado (Vieira, 1980).

A amostra da pesquisa é formada por docentes e discentes do Colégio de Aplicação da Universidade Iguaçu, localizada em Itaperuna - RJ, cidade situada na região sudeste do Brasil.

Os sujeitos da presente pesquisa foram vinte e quatro discentes escolhidos, utilizando as técnicas de amostragem estratificada e sistemática, onde foram escolhidos seis alunos de cada turma do ensino fundamental e cinco docentes da disciplina de ciências. (Vieira, 2003).

Finalizando, percebemos que o jogo, em que se centrou esta investigação, propiciou uma mudança de comportamento nas atitudes dos alunos envolvidos em relação a necessidade da preservação do meio ambiente. Essa mudança ocorreu tanto na escola, quanto no cotidiano familiar. Por outro lado, houve uma aprovação pelos professores da disciplina de ciências do ensino fundamental, pois consideraram estes jogos como uma importante ferramenta no processo de ensino aprendizagem.

\section{Referências Bibliográficas}

1. ANTUNES, Celso. (1998). 10ª . Ed. Petrópolis - RJ : Editora Vozes, pp. 295.

2. BRENELLI, Rosely Palermo. (1996). O Jogo como Espaço para Pensar. A Construção de Noções Lógicas e Aritméticas. Campinas, SP: Papirus.

3. CHIZZOTTI, Antônio. (2003). 6 ${ }^{\mathrm{a}}$. Ed. São Paulo - SP : Editora Cortez, pp.164.

4. CONFERÊNCIA DAS NAÇÕES UNIDAS SOBRE O MEIO AMBIENTE E DESENVOLVIMENTO (1996). A Agenda 21, Brasília : Senado Federal, Subsecretaria de Edições Técnicas.

5. GANE, Chris, SARSON, Trish. (1999). Análise Estruturada de Sistemas. 19. ed. Rio de Janeiro: Livros Técnicos e Científicos Editora, pp. 240-257

6. IGUINHO. Disponível em: <http://www.iguinho.com.br>. Acesso em: 10 setembro 2004.

7. JÚNIOR, Erasmo Nobre. Jogos em Flash MX - Criação e Desenvolvimento - Para Windows, editora Érica pp. 213.

8. MORIN, Edgar. (2001). Introdução ao pensamento complexo. $3^{\text {a }}$. Ed. Lisboa : Instituto Piaget, vol. 1, pp.177.

9. PIAGET, Jean. (1967). A psicologia da inteligência. Lisboa: Fundo de Cultura. 
10. TOM DA MATA. Disponível em: <http://www.tomdamata.org.br>. Acesso em: 12 setembro 2004.

11. VIEIRA, Sonia. (2003). Princípios de Estatística. 2003. 1a Edição. São Paulo: Pioneira Thomson Learning, pp. 143-144.

12. VIEIRA, Sonia. (1980). Introdução à Bioestatística. 3a Edição. Rio de Janeiro: Editora Elsevier.

13. VYGOTSKY, Lev S. (1984). A formação social da mente. São Paulo: Martins Fontes. 